\title{
Chapter 17 \\ Publish or Perish: British Medical \\ Journal Theme Issue, New England Journal of Medicine Series
}

"Publish or perish!" The governing principle of academia. Trite though it may be, true it also is. At any research university - and that is where medical schools are and where those who do research in patient safety work-you do not get promoted if you don't publish.

Medical journals publish science, or at least they try to. Was this new patient safety stuff science? There were those who did not think so. It was "soft stuff" — not as bad as psychiatry, perhaps—-but "touchyfeely" interpersonal stuff. It didn't seem to fit the mold of medical practice that many doctors embraced of treatment based on scientific evidence. This may have been part of the reason that the results of the Medical Practice Study were ignored when they came out, as were the recommendations in Error in Medicine a few years later.

In the "great awakening" of patient safety, in the post-Annenberg and pre-IOM days of patient safety when the NPSF was being formed, the Executive Session was underway, and IHI was establishing its breakthrough collaboratives, leaders of the movement were concerned that young investigators would not be able to get their work in the new science of patient safety published in leading journals where it needed to be for their academic advancement. Lacking that access would stifle innovation.

Leading American journals, NEJM and JAMA, had published the foundational papers, but little since. They and other journals still did not seem to regard this new field of patient safety as "science." NPSF had begun to fund research projects. Would the results be published? 
The breakthrough came, interestingly, from Britain. This was not altogether surprising: the two foremost thought leaders in patient safety, James Reason and Charles Vincent, were from the UK. Reason had been a featured speaker at Annenberg. The NHS Chief Medical Officer, Liam Donaldson, was beginning his work to bring patient safety to the fore. But it was Richard Smith, editor of the British Medical Journal (BMJ), who got it moving.

It was Richard Smith, you will remember, who in 1998 wrote in response to the Bristol Inquiry, "All changed, changed utterly. British medicine will be transformed by the Bristol case" [1]. Richard was a great fan of Don Berwick and had supported the NHS's involving Don in quality improvement. Smith was intrigued by the rising interest in patient safety.

In February 1999, he invited Don and me to edit a special theme issue of BMJ on medical error. We thought it was a terrific idea!

This was big stuff. Annenberg had been exciting, but it did not lead to much movement other than the founding of the NPSF. The public and the medical profession were still largely unaware of the extent of the problem of medical error or of efforts to implement systems changes. AHRQ hadn't yet been born. Don and I were on the IOM Quality Committee, but it had not issued "The Report." Publication of patient safety papers in BMJ would get doctors' attention. We were excited.

Richard gave us full latitude to select the topics and solicit papers. He asked us to commission five articles and five editorials and issue an open solicitation for an additional four original papers and several brief reports. This was going to be a far bigger publishing effort than anything Don or I had ever been involved in.

We wrote a call for papers - an editorial in BMJ - that laid out the problem and asked for submission of papers. We provided a substantial list of potential topics and indicated that we were interested in innovative topics, as well as authors from industry and other fields in addition to health care. The editorial was published on July 17, 1999 [2].

We then wrote to those we had selected to write commissioned papers. As we anticipated, all accepted. The papers were due by November, and our chosen authors produced them in record time. As we reviewed them, it became clear that this single issue of the journal would give an impressively comprehensive look at this new field of 
patient safety by the people who were making it happen. It would be a reference issue.

The BMJ special issue was published on March 18, 2000 [3], just months after the release of the IOM Report. Publication was timed to coincide with the first UK national symposium on medical error organized by the British Medical Association and the National Health Service, at which Don and I also spoke.

The papers were awesome: Jim Reason (error management) [4], Saul Weingart (epidemiology) [5], Bob Helmreich (lessons from aviation) [6], David Gaba (anesthesia as a model) [7], David Bates (IT and medication errors) [8], and Tom Nolan (systems changes) [9].

In addition to the commissioned papers and editorials by Dennis O'Leary (accreditation) [10], Jim Reinertsen [11] (disclosure), Michael Cohen (voluntary reporting) [12], and Albert Wu (second victim) [13], the final issue included 13 original papers and reports.

This was the first time that a major medical journal brought together in a single-issue works by international authorities on the major concepts in patient safety and results from empirical studies. Smith gave it a real boot by putting a photograph of a crashed airliner on the cover of that issue of the staid old BMJ!

It had an enormous impact. BMJ is the primary medical journal for all of Europe and is read by many around the world. The special issue put safety on the screen for the first time for many people. At least one of my safety friends, Beth Pedersen Lilja from Copenhagen, later told me that it did that for her-and led her and others to come to the Salzburg Seminar the next year.

\section{NEJM Series on Patient Safety}

Later that year, in the fall of 2000, I drafted a letter to the editor of the New England Journal of Medicine (NEJM) asking whether they would be willing to consider publishing a series of essays on issues in patient safety. I showed it to my department chairman, Arnie Epstein, who was an Associate Editor at the NEJM. He was supportive, but he thought a more successful approach might be for him to sound out the editor in chief and the other editors and try to persuade them to take it on. The fact that a major rival, the BMJ, had devoted a special issue to patient safety might have sparked some interest. 
I really wanted them to do this. Having your paper published in the NEJM is the official stamp of quality in academic medicine. The Journal has the largest circulation of any medical journal in the world and is trusted by physicians and health policy people as the most reliable source of medical information. As a result, it attracts reports of leading-edge medical research and "breakthroughs."

The IOM report brought national attention to patient safety, but it was a book, and most doctors don't have time to read books. They do read journals, though, and in the USA, the NEJM is at the top of the pile. The American readers of the BMJ Special Issue were mostly academics. This would be an opportunity to reach a broad range of doctors and policy makers and increase their awareness and understanding of the major issues in patient safety. If we did it right, patient safety papers published in the NEJM might make them more likely to accept the changes we were proposing and motivate some to join in the work. It would also, of course, spread the word around the world.

About 8 months after that conversation, I finally got the call. They were interested. Arnie and I met with Jeff Drazen, the Editor in Chief, to negotiate the deal — what the series would consist of, who decided, and how to proceed. It was a bit complicated, but we worked it out, and the Deputy Editor, Robert Steinbrook, was assigned to work with me and Arnie to come up with a proposal.

We agreed that the purpose of the series would be to explain key issues in patient safety and to stimulate interest and debate that would influence health policy. We would choose topics that were central to safety and provide fresh analysis, showing how new approaches could provide remedies. The series would include up to 12 papers, published monthly. The proposal was accepted.

The process was much more complicated than it had been with the BMJ, where Don Berwick and I were given carte blanche to pick the subjects and authors and were able to do it quickly. With the NEJM, we had to convince the editors of the worth of each subject and the competence of our chosen author to deliver. The papers would be subject to the usual lengthy review process.

I developed a list of 14 potential topics and wrote a brief on each one, outlining the issues of interest and the questions to be addressed by the paper. These would also be the instructions for the authors. 
Arnie, Robert, and I had extensive discussions about whom to invite to write the papers. We read previous papers written by candidates and consulted widely with colleagues about their suitability. If the papers were to be definitive statements of the current state of the art, the authors needed to be unquestioned experts.

We recommended 12 topics to the editors. After some discussion they decided to start with 6 and later consider expanding that number. I was disappointed, but "half a loaf...." We narrowed it to six and gave the editors a brief on each one with the proposed author. They were accepted, and I invited the authors to write the papers. Fortunately, we did ultimately get 12 papers published.

The process took a year, but the series finally began in October 2002 with a bang: five papers in one issue of the Journal. The editors decided to take advantage of the recently aroused interest in a specific safety issue, resident work hours. The Accreditation Council on Graduate Medical Education (ACGME) had announced they would be requiring an 80 hours per week limitation of resident work hours as of July 1, 2003. The rule had sparked a vigorous and sometimes acrimonious debate within the profession. The editors decided to focus on that issue, which, interestingly, had not received much attention in the IOM report.

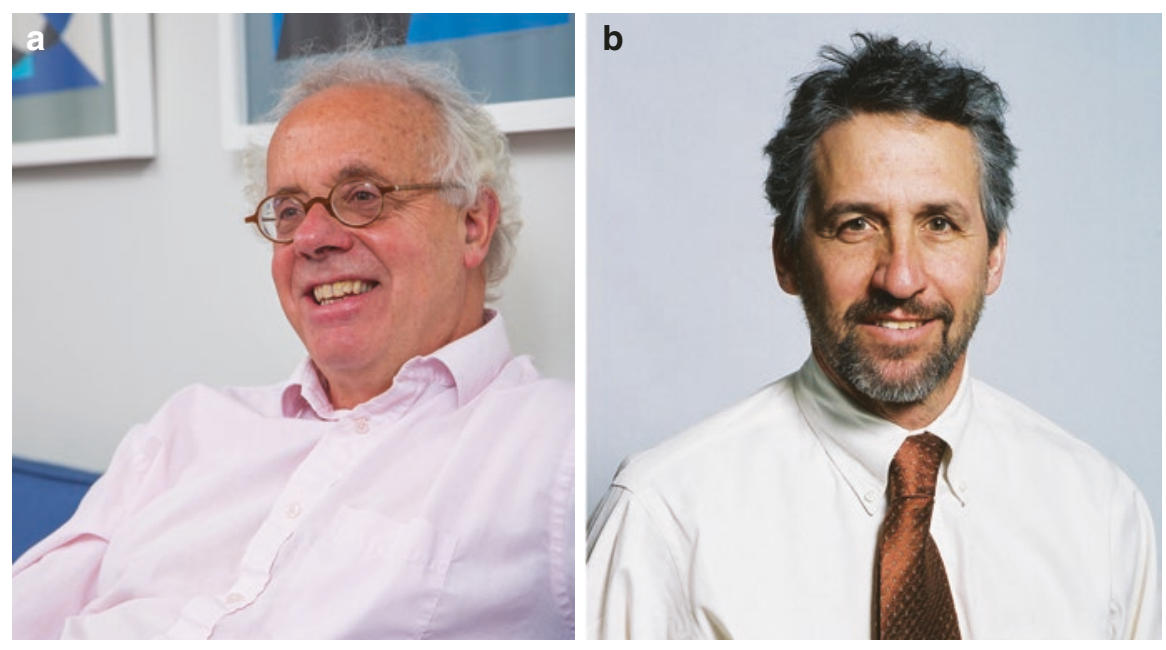

(a) Richard Smith, and (b) Arnie Epstein. (All rights reserved) 
So, in addition to our overview editorial about the series and David Gaba and John Howard's commissioned paper on physician fatigue, the issue contained an editorial on rethinking medical training by Drazen and Epstein, a Sounding Board article on duty hours by Debra Weinstein, and a Health Policy Report on the debate over resident's hours by Steinbrook.

Gaba and Howard's paper, Fatigue among Physicians and the Safety of Patients, reviewed the scientific evidence of the effects of fatigue on performance and the efforts to limit MD hours [14]. They analyzed the new ACGME regulations and their consequences. Drazen and Epstein's Rethinking Medical Training - The Critical Work Ahead emphasized the enormous importance of the issue and that it was an opportunity to rethink residency training. The measure of success will be whether it is improved [15].

Debra Weinstein's Duty Hours for Resident Physicians explored the consequences of hour reduction and the need to reengineer the system of care [16]. Steinbrook's The Debate Over Resident's Work Hours provided facts about residency numbers, reviewed the arguments for and against the change, and examined the details of the requirements and problems in implementation [17].

Having multiple papers on the same subject might seem like overkill, but it was not. The overlapping messages presented in different contexts reinforced the impact. The overall message was clear: limits to work hours were here to stay, and the consequences would be substantial and difficult to cope with.

The Journal then featured one safety paper each month. The one in November was my paper on reporting [18]. This was the issue in the IOM report that had attracted the most interest-and misunderstanding. Immodestly, I saw this as an opportunity to write the definitive work on the subject!

\section{Reporting of Adverse Events}

A year before the IOM report, in October 1998, I sent a memo to the key thinkers, Don Berwick, Richard Cook, David Woods, David Bates, David Gaba, David Cullen, and Jeff Cooper, asking whether we should work on developing a proposal for a national medical 
adverse event reporting system. I extolled the virtues of the Aviation Safety Reporting System that we were all familiar with and asked if we should have something like it.

They agreed to consider it. There was an obvious problem with this idea: the Aviation Safety Reporting System gets 30,000 reports a year at a cost of \$two million. Extrapolation from our incident studies suggested we could have as many as three million. Do the arithmetic!

In lieu of such a national system, we considered the alternative of hospital level reporting. To succeed would require major efforts by CEOs to create an environment where nurses and others felt safe reporting. Even if it were limited to sentinel events or sampling events one day a month, it would yield more reports than they could handle. A confidential system reporting near misses would face similar barriers. We decided not to pursue it further.

Writing my paper for the NEJM did not go well. Because their whole process around producing the papers was so controlling, I was unsure of whether what I was writing was appropriate, so I sent a draft to Jeff Drazen for his suggestions before finalizing the paper. Was it what he wanted? To my dismay, we miscommunicated, and rather than giving me advice, he sent the draft out for reviews! It was not ready, and by the time I found out it was too late to call it back.

One of the reviewers was the former editor of the Journal, Arnold (Bud) Relman. We were old friends, but that didn't inhibit his professionalism. He chopped away at it. He was particularly offended that I made a reference to something he had said or written without giving citation credit. I had planned to do that, of course, but this was a draft. I called him, explained that the paper was a draft, and apologized. His review, of course, was very helpful. I rewrote the paper, and it survived the final round of reviews.

The paper, Reporting of Adverse Events, analyzed the objectives, potential, practices, success, and limitations of current reporting systems, both voluntary and mandatory [18]. It analyzed the characteristics of successful reporting systems. I noted that a national voluntary reporting program that provides meaningful analysis of events and feedback of useful information (such as the aviation reporting system) would be quite expensive and, therefore, unlikely to be developed. Existing state mandatory reporting systems had limited value for the 
same reason. On the other hand, numerous voluntary specialty-based and system-wide reporting systems were developing and seemed to be quite successful.

At the time of the report, 20 states had mandatory reporting systems that varied widely in requirements. The publication of the list of "Never Events" by the NQF the previous year led some states to standardize mandatory reporting around clearly defined and non-debatable events. It also stimulated others to create reporting systems. By 2010, 27 states and the District of Columbia had mandatory reporting systems.

In December, the NEJM published a survey they had commissioned from Bob Blendon: Views Of Practicing Physicians And The Public On Medical Errors [19]. In January 2003, the series resumed on a monthly basis with Atul Gawande's Risk Factors for Retained Instruments and Sponges after Surgery [20], John Burke's Infection Control - A Problem for Patient Safety [21], Charles Vincent's Understanding and Responding to Adverse Events [22], and David Bates and Gawande's Improving Safety with Information Technology [23]. The commissioned paper on malpractice did not survive the review process; it was replaced by a paper by Tejal Gandhi, Adverse Drug Events in Ambulatory Care [24].

The Journal decided this was enough for now. I was disappointed because I thought several other subjects deserved airing: Organizational Change, Nursing, Institutional and Professional Oversight, Regulation, and the VA as a case study. However, the papers published in the series were excellent: informative, provocative, and authoritative. I think they made a difference.

\section{Patient Safety and Quality Journals}

The embrace of patient safety by the premier medical journals did indeed seem to have the desired effect of providing academic respectability for the new field of patient safety. Other mainstream journals and specialty journals began to publish more safety-related articles. Junior faculty could now get their papers published. 
It is important to note, however, that within the quality and safety community, there were several major outlets that had been publishing research papers for some time. Three deserve comment: the Joint Commission Journal on Quality and Safety, BMJ's Quality in Health Care, and the Journal of Patient Safety.

\section{Joint Commission Journal on Quality Improvement and Safety}

The Joint Commission was an early leader in the quality improvement movement. In 1974 it created one of the first journals dedicated to quality improvement, the Quality Review Bulletin (QRB). The name was changed to the Joint Commission Journal on Quality Improvement in 1993, and then, as the patient safety movement got under way, to the Joint Commission Journal on Quality Improvement and Safety in 2003. Published monthly, the Journal has been the major venue for publication of actual protocols and safety practices, such as the two from the Massachusetts Coalition on Reconciling Medications and Communication of Critical Test Results [25, 26].

\section{BMJ's Quality and Safety in Health Care}

In 1992, 8 years before the BMJ special issue, its editor, Richard Smith, decided to give greater emphasis to the burgeoning field of quality improvement and created a subsidiary journal, Quality in Health Care. It soon became a major journal for publication of quality of care research, rivaling or surpassing the Joint Commission's journal.

The journal added patient safety to its remit in 2011 when it changed its name to Quality and Safety in Health Care and hired Kaveh Shojania as editor. Currently, it publishes more articles than any other quality or safety journal and is a major voice for patient safety research. 


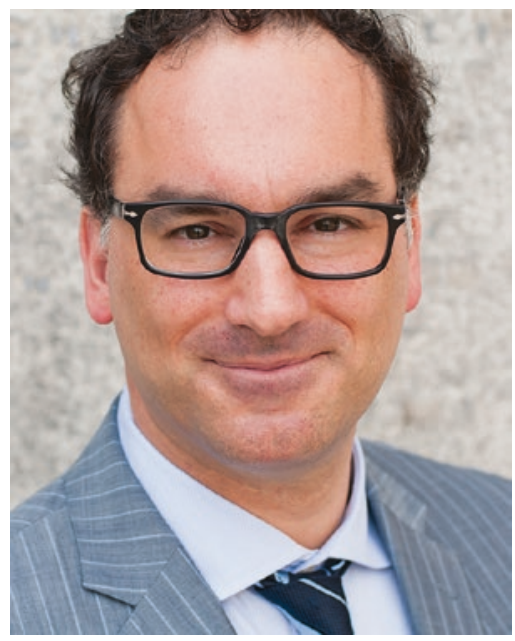

Kaveh Shojania. (All rights reserved)

\section{The Journal of Patient Safety}

The latest entry to the field, the Journal of Patient Safety, was created as the official journal of the National Patient Safety Foundation in 2005 under the leadership of Nancy Dickey, former Chairman of the Board of the AMA. As a new journal, it had trouble attracting papers from researchers because of low readership, but it was gaining impact until the Denham scandal (Chap. 5). He had published a number of his own papers, later review of which showed numerous conflicts of interest.

In 2014, David Bates took over as editor. Under his leadership, the Journal has prospered. Although it is a quarterly journal, it now publishes a large number of papers in each issue and has proven to be a valuable patient safety resource.

\section{Conclusion}

Academic journals are the lifeblood of research. "If it isn't published, it didn't happen" may be a bit of an exaggeration, but not much. New ideas have to be communicated to get traction; word of mouth and 
presentations at meetings are not enough to do the job. Most importantly, the peer-review process filters out most (not all) bad research; good studies prompt others to replicate them and often inspire new ideas. All of these journals - the prestigious and the patient safetyoriented-have, in fact, established patient safety as a discipline that is here to stay.

\section{References}

1. Smith R. All changed, changed utterly. BMJ. 1998;316(7149):1917-8.

2. Berwick DM, Leape LL. Reducing errors in medicine [editorial]. BMJ. 1999;319(7203):136-7.

3. Leape LL, Berwick DM. Reducing error, improving safety [special issue]. BMJ. 2000;320(7237):725-814.

4. ReasonJ.Humanerror:modelsandmanagement.BMJ.2000;320(7237):768-70.

5. Weingart S, Wilson R, Gibberd R, Harrison B. Epidemiology of medical error. BMJ. 2000;320(7237):774-7.

6. Helmreich RL. On error management: lessons from aviation. BMJ. 2000;320(7237):781-5.

7. Gaba D. Anaesthesiology as a model for patient safety in health care. BMJ. 2000;320(7237):785-91.

8. Bates DW. Using information technology to reduce rates of medication errors in hospitals. BMJ. 2000;320(7237):788-91.

9. Nolan TW. System changes to improve patient safety. BMJ. 2000;320(7237):771-3.

10.O'Leary D. Accreditation's role in reducing medical errors. BMJ. 2000;320(7237):727-8.

11.Reinertsen J. Let's talk about error. BMJ. 2000;320(7237):730.

12.Cohen MR. Why error reporting systems should be voluntary. BMJ. 2000;320(7237):728-9.

13.Wu A. Medical error: the second victim. BMJ. 2000;320(7237):726-7.

14. Gaba DM, Howard SK. Fatigue among clinicians and the safety of patients. N Engl J Med. 2002;347(16):1249-55.

15.Drazen JM, Epstein AM. Rethinking medical training--the critical work ahead. N Engl J Med. 2002;347(16):1271-2.

16. Weinstein DF. Duty hours for resident physicians--tough choices for teaching hospitals. N Engl J Med. 2002;347(16):1275-8.

17. Steinbrook R. The debate over residents' work hours. N Engl J Med. 2002;347(16):1296-302.

18.Leape LL. Reporting of adverse events. N Engl J Med. 2002;347(20):1633-8. 
19. Blendon RJ, DesRoches CM, Brodie M, et al. Views of practicing physicians and the public on medical errors. N Engl J Med. 2002;347(24):1933-40.

20. Gawande AA, Studdert DM, Orav EJ, Brennan TA, Zinner MJ. Risk factors for retained instruments and sponges after surgery. $\mathrm{N}$ Engl $\mathrm{J}$ Med. 2003;348(3):229-35.

21.Burke JP. Patient safety: infection control - a problem for patient safety. $\mathrm{N}$ Engl J Med. 2003;348(7):651-6.

22. Vincent C. Understanding and responding to adverse events. N Engl J Med. 2003;348(11):1051-6.

23. Bates DW, Gawande AA. Improving safety with information technology. N Engl J Med. 2003;348(25):2526-34.

24.Gandhi T, Weingart SN, Borus J, et al. Adverse drug events in ambulatory care. N Engl J Med. 2003;348:1556-64.

25.Rogers G, Alper E, Brunelle D, et al. Reconciling medications at admission: safe practice recommendations and implementation strategies. Jt Comm J Qual Patient Saf. 2006;32:37-50.

26. Hanna D, Griswold P, Leape L, Bates D. Communicating critical test results: safe practice recommendations 2005. Jt Comm J Qual Patient Saf. 2005;31:68-80.

Open Access This chapter is licensed under the terms of the Creative Commons Attribution 4.0 International License (http://creativecommons.org/ licenses/by/4.0/), which permits use, sharing, adaptation, distribution and reproduction in any medium or format, as long as you give appropriate credit to the original author(s) and the source, provide a link to the Creative Commons license and indicate if changes were made.

The images or other third party material in this chapter are included in the chapter's Creative Commons license, unless indicated otherwise in a credit line to the material. If material is not included in the chapter's Creative Commons license and your intended use is not permitted by statutory regulation or exceeds the permitted use, you will need to obtain permission directly from the copyright holder.

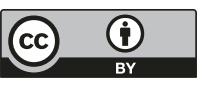

